\title{
Model of an Integrated Procurement-Production System for Food Products Incorporating Quality Loss during Storage Time
}

\author{
Gusti Fauza, Yousef Amer, and Sang-Heon Lee
}

\begin{abstract}
Research on procurement-production systems for deteriorating items has been done. The majority of studies assume that the perishable characteristics affect only the quantity of inventoried items. For food products, however, their quantity remains constant during their shelf life period, but the quality deteriorates over time. This paper proposes a new procurement-production model incorporating this situation. The quality change behavior of food products is approached differently depending on their forms either as raw materials or finished goods. As raw materials, the kinetic model is used to represent the quality degradation during storage time, while as finished goods the shelf-life dependent pricing is utilized to describe the value loss due to the quality perception of customers. A mathematical model representing the integrated procurement-production of raw materials and finished goods at a manufacturer is established in this research. The objective is to maximize the total profit per unit time of the system by controlling a number of variables, namely the production cycle $(T)$, the number of raw materials' procurement over one production cycle $(m)$ and the number of finished goods delivery over one production cycle $(n)$.
\end{abstract}

Index Terms-Deteriorating items, food inventory, procurement-production system, quality loss, value loss.

\section{INTRODUCTION}

Ever since EOQ (Economic of Quantity) inventory control has been introduced, many researchers still develop it to solve various inventory problems. Conventionally, economic lot-size of raw materials was decided separately from finished product and this may lead to sub-optimization. It is because demand for raw materials depends on production schedule of finished products. Later, Goyal [1] developed an integrated inventory model for raw material and finished product. This research gave the first contribution in the field of integrated procurement-production (IPP) systems.

Recently, research in the field of IPP system receives significant attention from scholars and many inventory models has been developed to accommodate this issue [2]. Goyal and Deshmukh [3] developed a model for IPP systems in just in time JIT environment to minimize set up time. And later, Lee [4] extend the IPP to an integrated supply chain problem by integrating the economic lot size of raw material, manufacturing set up and finished products. However, those studies assume that items can be stored infinitely, while in

Manuscript received November 5, 2012; revised January 10, 2013.

Gusti Fauza is with the School of Engineering, University of South Australia and Food Science and Technology Department, Sebelas Maret University, Indonesia (email: faugy001@mymail.unisa.edu.au).

Yousef Amer and Sang Heon Lee are with the School of Engineering, University of South Australia. fact, some items have limited life time.

In reality, it is often found that some particular items deteriorate over the storage period, for instance food products. For such items, the quality degradation during the storage time can lead to a significant waste or loss. To illustrate, an FAO study reported that every year 1.3 billion tones food are wasted globally [5]. The major food losses occur in producer-retailer stage and the mismatch between production and demand is identified as the main cause. Noting this situation, it is crucial to incorporate the perishability characteristics of the items while managing the inventory.

Actually, studies on integrated inventory models for perishable items have been done [6]-[8]. However, those models assume that the deterioration of the items leads to the quantity decrease, as observed in the inventory of gasoline, alcohol or radioactive materials. Certainly, these assumptions are not suitable for food products. The quantity of food typically remains the same during their shelf-life, while their quality, which can be represented by the freshness, obviously degrades. In addition, it is also assumed in the previous models that the deterioration characteristics of the raw materials and the finished goods are identical. But food is a dynamic item [9]. The perishable characteristics of food are not identical and need to be approached differently. Therefore, the existing models are inadequate for representing the inventory systems of food products.

This paper proposes a new model of food inventory in the IPP system incorporating quality loss during storage time. Unlike the previous research in this field, the proposed model approaches deteriorating characteristics for raw materials and finished goods in different ways.

The remaining sections of this paper are organized as follows: Section 2 contains a review of existing inventory models for perishable items, while Section 3 discusses the modeling of quality degradation of raw materials. Moreover, Section 4 presents model for the quality of finished goods, or called value loss model. The complete model of an integrated procurement-production system for food products is covered in Section 5, while the last section, Section 6, summarizes this paper.

\section{LITERATURE REVIEW}

In this literature review, two groups of studies on the deteriorating inventory model are discussed. The first group includes models that address quantity decay as the result of storage time, while the second one covers models that deal with value or utility decrease. 
Research in the first group is based on the assumption that during the inventory period, the inventory level is depleted by demand and deteriorated items. This deteriorating phenomenon was accommodated into an EOQ model by Ghare and Schrader [10] using a differential equation as can be seen from (1).

$$
\frac{d I(t)}{d t}+\theta I(t)=-D(t)
$$

where $I(t)$ refers to the inventory level, $D(t)$ represents the demand rate at time $t$, and $\theta$ is the deteriorating rate of the item. Park [6] extended the deteriorating models into an integrated procurement-production problem. He assumed that only raw materials decayed during the production cycle. Later, Raafat [11] developed it and used the more realistic assumption that the finished good deteriorated as well. Recently, other scholars [12] and [13] advanced the integrated inventory model by implementing a multishipment policy in a multi-echelon system.

While studies in the perishable inventory model in the first group were showing quantity decrease as the result of perishable items, research in the second group was focusing on value and utility decay instead. Weiss [14] charged a non-linear holding cost on EOQ models. A few years later, Ferguson, et al. [15] applied this model to manage perishable inventories. Similarly, Fujiwara and Perera [16] viewed this problem from a utility perspective. They used both linear and exponential penalty cost charged for every perishable item held in storage as the usability of the products decayed over time. Recently, Blackburn and Scudder [17] developed a supply chain strategy for perishable products by considering fresh produce value decrease through a supply chain.

Comparing models in those two groups, the approaches in second group are more suitable for food products. However, these models are still insufficient to represent food inventory model in an integrated procurement-production system. They still ignore the fact that the raw materials supplied for production should not be procure separately from finished goods production planning. In addition, the assumption of an identical deteriorating characteristic is still used. Therefore, there is a need to revisit those models and revise them into a new model which is more appropriate in representing inventory model for food products in the integrated procurement-production system.

\section{MOdELING THE QUALITY DEGRADATION OF RAW FoOD MATERIALS}

As explained in Section 1, in this paper, the quality degradation in raw materials is approached differently with that in finish goods. An interesting approach on accommodating quality degradation in production has been proposed by Rong, et al. [18]. They employed quality loss function model to describe quality degradation of food during distribution time. A quantitative approach, called kinetic model, is adopted to represent the quality loss of raw food materials. In this model, the quality of the items degrades depending on environment and time of storage as illustrated by (2).

$$
\frac{d q}{d t}=k q^{n}
$$

$q$ represents the quality factor measured depending food characteristics and $t$ is time, which usually in months for more stable food and in days for more deteriorating food. Meanwhile, $k$ is the rate of deterioration depending on storage environment (e.g. temperature, activation energy, gas constant) and $n$ denotes a power factor or the reaction order [19]. The value of $n$ influences the pattern of the quality loss as described by Fig. 1 .

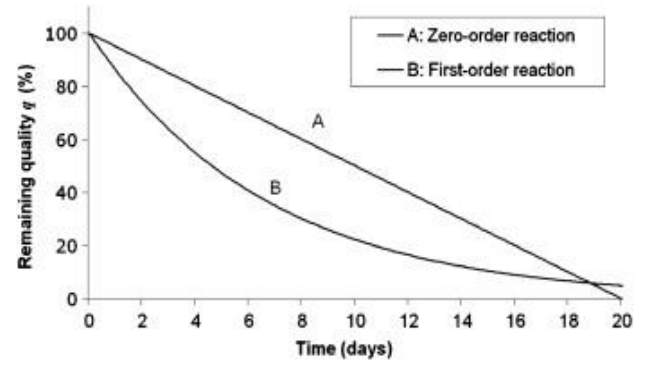

Fig. 1. Quality degradation illustration of food products [18].

For $n=0$, or called zero order reaction, the quality decreases linearly over time as represented by line A in Fig.1. Alternatively, for $n=1$, or called first-order reaction, the quality degrades exponentially as illustrated by line B at the same figure. Based on the phenomena in this figure, the inventory model of raw materials accommodating quality loss will be developed.

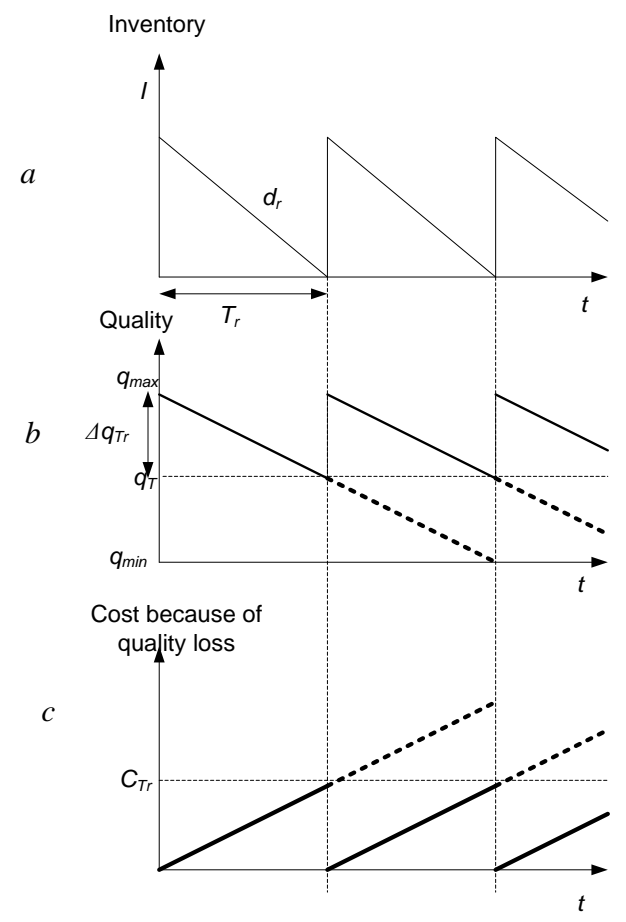

Fig. 2. The relation between inventory, quality and cost of raw food materials.

Generally, the majority research in deteriorating inventory assumed that during the shelf life period, the quality of the items is constant. This assumption, however, ignore the fact, which is shown in Fig. 1, that the food quality degrades during storage time; the longer the items are stored, the more their quality degrade. This degradation could affect the quality of final products and could lead to a higher cost for maintaining product quality. Therefore, these issues need to be addressed carefully in deteriorating inventory model to provide a more realistic model in presenting food characteristic. The relation between quality, quantity, time 
and cost is illustrated by Fig. 2 .

In Fig. $2 a$, inventory $(I)$ is depleted only by demand $\left(d_{r}\right)$. Moreover, all inventoried items are in their maximum quality $\left(q_{\max }\right)$ at the beginning of the procurement cycle $(t=0)$. However, by the time, as can be seen from Fig. $2 b$, the quality of raw material linearly degrades during the period $t, t+d_{r} t$, called $\Delta q(t)$. Every single item which suffers from the quality loss will be charged by quality cost $C$ which linearly increases over time (Fig. $2 c$ ). It means that, the longer items stored in the storage, the higher cost of quality. Thus, adapting Fujiwara and Perera [16] approach, the cost of the raw material quality loss $(L)$ during one replenishment cycle $\left(T_{r}\right)$ can be represented by (3).

$$
L=\int_{0}^{T_{r}} C d_{r} \Delta q(t) d t
$$

\section{Modeling VAlue Deterioration of Finished Food PRODUCTS}

Generally, in reality, customers realize that the quality of food products deteriorates over time. Although customers may not have direct access to examine the quality of food products, they can judge them from the products' remaining lifetime by seeing the products' best before date (BBF). In this situation, customer prefer to buy products with longer remaining lifetime or later BBF which are judged as 'fresher' [20]. Tsiros and Heilman [21] reported that customers' willingness to pay (WTP) decrease as the product's lifetime gets closer to its BBF. It means that even though a product is still in its shelf-life period, the value of the product could loss. This value loss needs to be handled properly as it can influence companies' sales benefit. The relation between benefit and remaining lifetime is illustrated by Figure 3 .

In Fig. 3, benefit $b$ is a linear function of remaining lifetime $t$. In this case, $\mathrm{t}$ is come from shelf life $T_{S L}$ minus storage time $T_{S T}$. If $t$ is equal to $T_{S L}$, which means there is no $T_{S T}$ or $T_{S T}=0$, then manufacturer will get maximum benefit $(\operatorname{Max} b)$. Otherwise, if $t$ is equal to customers' minimum requirement of product's remaining life time $T_{\text {min }}$, manufacturer will gain no benefit.

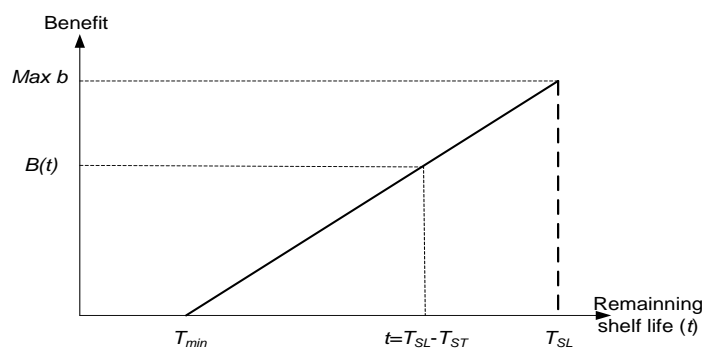

Fig. 3. The relation between shelf life, remaining shelf life and sales benefit [adapted from 20].

Equation (4) shows the linear correlation between benefit $b$ and remaining life time $t$.

$$
b(t)=\frac{M a x b}{T_{S L}-T_{\min }} \cdot t+A
$$

If $t$ is equal to $T_{\min }$, then $b\left(T_{\min }\right)$ will be equivalent to zero. Consequently, the value of $A$ (constant) will be equal to (5).

$$
A=-\frac{\operatorname{Max} b}{T_{S L}-T_{\min }} \cdot T_{\min }
$$

substituting (5) to (4) leads to (6).

$$
b(t)=\frac{M a x b}{T_{S L}-T_{\min }} \cdot\left[T_{S L}-T_{\min }-T_{S T}(t)\right]
$$

Equation (6) shows that since the $T_{S L}$ and $T_{\min }$ are fixed and given, the length of storage time or $T_{S T}$ becomes the only factor which reduces benefit $b$. In other words, the longer the items are stored in the storage, the more they will lessen the benefit.

\section{The Proposed Model for Quality and Value DEGRADATION IN AN INTEGRATED PROCUREMENT-PRODUCTION SYSTEM}

In this section, the quality loss of raw material and the value degradation of finished goods will be integrated into an integrated procurement-production system. The interaction between both deterioration types will affect the inventory policy, namely, the production cycle, raw material ordering and frequency of the delivery of finished goods. The best value of those decision variables will lead to the companies' maximum profit.

This proposed model will use the following notations and assumptions

$\begin{array}{lll}\text { Notation } & & \\ d_{r} & : & \text { Raw materials' demand rate }\left(d_{r}=P\right) \\ d_{p} & : & \text { Finished goods' demand rate }\left(d_{p}>P\right) \\ P & : & \text { Production rate } \\ m & : & \text { Raw materials' ordering frequency } \\ n & : & \text { Finished goods' delivery frequency } \\ o & : & \text { Ordering cost } \\ s & : & \text { Set up cost } \\ a & : & \text { Delivery cost } \\ h_{r} & : & \text { Raw materials' holding cost } \\ h_{p} & : & \text { Finished goods' holding cost } \\ C & : & \text { Cost of quality loss } \\ T_{r} & : & \text { Raw materials' replenishment cycle } \\ T_{p} & : & \text { Production run length } \\ T & : & \text { Production cycle time } \\ T_{S T} & : & \text { Storage time } \\ T_{S L} & : & \text { Product shelf life } \\ T_{\min } & : & \text { Customers' requirement of minimum } t \\ T_{d} & : & \text { Delivery cycle of finished good } \\ t & : & \text { Product remaining shelf life where } t=T_{S L}-T_{S T} \\ M a x b & : & \text { Company's maximum benefit when } t=T_{S L} \text { or } T_{S T}=0 \\ b(t) & : & \text { Company's benefit depending } t \\ B(T, m, & : & \text { Company's total profit } \\ n) & & \end{array}$

\section{Assumptions}

1) The rate of demand and production is constant during cycle time where $P>d_{p}$

2) The quality degradation of the raw food material is constants $(n=0)$

3 ) The deterioration of the value of the finished goods during storage time $\left(T_{S T}\right)$ is constant

4) The shelf life of raw materials is set to be longer than the replenishment cycle $\left(t_{\text {qmin }} \geq t_{s l}\right)$

5) No shortage or backlog is allowed

The characteristic of this system is illustrated by Fig. 4. 
Fig. 4a shows that the raw material fulfills the production demand $d_{r}$ in batches $m$ during the production run time $T_{p}$. The total cost per unit time for raw materials $T C_{r}$ consists of ordering cost, holding cost and cost of quality loss which are then divided by production cycle $T$. The shaded area of the triangle figure represents the total inventory of raw materials during $T$, which is equal to $1 / 2 q_{r} T_{p}$. Since $q_{r}$ is identical to $d_{p} T / m$ and $T_{p}$ is the same with $d_{p} T / P$, as a result the total inventory of raw material is equivalent with $\frac{1}{2} \frac{d_{p}^{2} T}{m p}$. Adjusting Eq. 3 and combining it into ordering cost and holding cost is equivalent to the total cost of raw materials per unit time (7).

$$
T C_{r}(T, m)=\frac{1}{T}\left\{\begin{array}{c}
o m+h_{r} \frac{d_{p}{ }^{2}}{P} \frac{T^{2}}{m} \\
+C d_{r} \int_{0}^{\frac{d p}{m p} T} \Delta \mathrm{q}_{r}(t) d t
\end{array}\right\}
$$

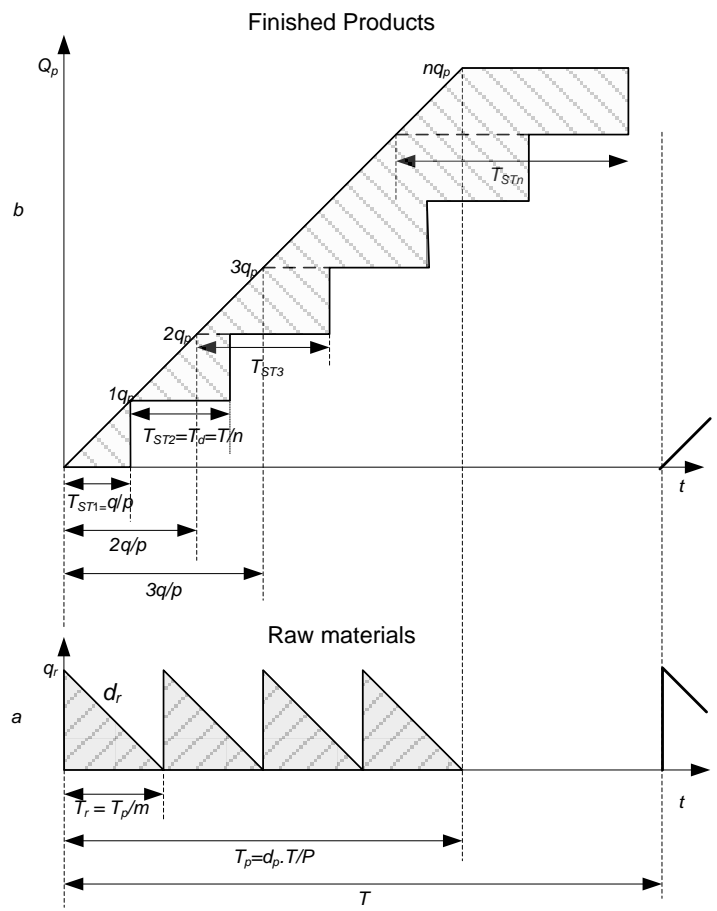

Fig. 4. The behavior of the IPP system.

On the other hand, finished products figure (Fig.4b) shows that the production rate is higher than customers' demand rate and causes inventory of finished goods (represented by shaded area). In addition, the finished goods deliver to retailer using multi-shipment delivery policy[18]. Hence, the total cost of finished goods (8) is composed by delivery cost per unit time, set up cost and holding cost per unit time.

$$
T C_{p}(T, n)=\frac{a n+s}{T}+h_{p} \frac{d_{p} T}{2 n}\left\{\frac{(2-n) d_{p}}{P}+n-1\right\}
$$

In addition, as mentioned before in Section VI, the sales benefit depends on the product's remaining shelf life $t$ (6). In this case, $t$ is equal to product shelf life $T_{S L}$ minus storage time $T_{S T}$ (Fig. $4 b$ ). $T_{S T}$ is defined as completion time of the product (in batch) minus the time when the product start to be produced. For first batch or $n=1, T_{S T}$ is equal to $q_{p} / p$ and for $n=2, T_{S T}$ is equal to $T_{d}$ or $T / n$. The mathematical function to express the storage time for $n$ batch is represented by (9). Substituting this function to (6), leads to total benefit $b(10)$

$$
\begin{gathered}
T_{S T_{n}}=(n-1) \frac{T}{n}+\frac{d_{p} T}{n P}(2-n) \\
b=\frac{M a x B}{T_{S L}-T_{\min }} \cdot \sum_{n=1}^{N} T_{S L}-T_{\text {min }}-(n-1) \frac{T}{n} \\
+\frac{d_{p} T}{n P}(2-n)
\end{gathered}
$$

Finally, the manufacturer's total profit, $B(T, m, n)$, which is equal to total benefit $b$ minus both total cost of raw materials $T C_{r}$ and finished goods $T C_{p}$ is represented by (11).

$$
\begin{aligned}
& =\frac{1}{T}\left[\begin{array}{c}
\left(\frac{M a x b}{T_{S L}-T_{\min }} \cdot \sum_{n=1}^{N} T_{S L}-T_{\min }-(n-1) \frac{T}{n}+\frac{d_{p} T}{n P}(2-n)\right) \\
-\left(o m+h_{r} \frac{d_{p}{ }^{2}}{P} \frac{T^{2}}{m}+m C d_{r} \int_{0}^{\frac{d_{p}}{m p} T} \Delta \mathrm{q}_{r}(t) d t\right)
\end{array}\right] \\
& -\left[\frac{a n+s}{T}+h_{p} \frac{d_{p} T}{2 n}\left\{\frac{(2-n) d_{p}}{P}+n-1\right\}\right]
\end{aligned}
$$

Equation 11 shows that integrating the result of deterioration of raw materials and finished goods affects the value of the inventory policy $(T, m, n)$. Therefore, ignoring these deteriorating characteristics may lead to less than best decision in managing perishable items such as food products.

\section{CONCLUSION}

A new model for IPP system has been developed in this paper. The model is more appropriate for food products for several reasons. Quality degradation and value loss, which are the main characteristics of perishable food, have been addressed in the model. The different quality degradation impacts on the inventory of two perishable items, either raw food materials or finished food products, have been considered. Therefore, this model is more realistic in representing the food inventory in IPP system.

In addition, the mathematical model of the objective function (the company's total profit) has been developed to examine the observed system. Three decision variables, namely, the production cycle $(T)$, raw materials ordering frequency $(m)$ and the finished product delivery number $(n)$ are identified and need to be optimized for the IPP's maximum profit.

However, there are some limitations in this research waiting for the future research. First, the proposed model only considers food inventory problems at manufacturing level or known as a single-stage perspective, while managing food is very complex and need to be viewed from an integrated supply chain or multi stage perspective. Second, in food preservation theory, the quality loss actually can be controlled by adjusting the temperature, so this is another important factor to be considered. Finally, a constant quality degradation $(n=0)$ has been assumed in the model, while in fact, some food has an exponential quality degradation or $n=1$ [9]. Therefore, for future development, it is expected to be able to revise these limitations to a more representative food inventory model. 


\section{ACKNOWLEDGMENT}

This work was supported by the Australian Government Overseas Aid Program (AusAid).

\section{REFERENCES}

[1] S. K. Goyal, "An integrated inventory model for a single product system," Operational Research Quarterly (1970-1977), vol. 28, pp. 539-545, 1977.

[2] S. K. Goyal and S. Deshmukh, "Integrated procurement-production systems: Areview," European journal of operational research, vol. 62 , pp. 1-10, 1992.

[3] S. Goyal and S. Deshmukh, "Integrated procurement-production system in a just-in-time environment-modelling and analysis," Production Planning and Control, vol. 8, pp. 31-36, 1997.

[4] W. Lee, "A joint economic lot size model for raw material ordering, manufacturing setup, and finished goods delivering," Omega, vol. 33, pp. 163-174, 2005.

[5] J. Gustavsson, C. Cederberg, U. Sonesson, R. van Otterdijk, and A. Meybeck, "Global food losses and food waste," Food and Agriculture Organization of the United Nations, Rom, 2011.

[6] K. S. Park, "An integrated production-inventory model for decaying raw materials," International Journal of Systems Science, vol. 14, pp. 801-806, 1983.

[7] F. Raafat, "Inventory systems of age-independent perishable items subject to on-going deterioration," Oklahoma State University, 1982.

[8] H. Rau, M. Y. Wu, and H. M. Wee, "Integrated inventory model for deteriorating items under a multi-echelon supply chain environment," International Journal of Production Economics, vol. 86, pp. 155-168, 2003.

[9] D. R. Heldman, "2 - Kinetic models for food systems," in Food Preservation Process Design, ed San Diego: Academic Press, 2011, pp. 19-48.

[10] P. Ghare and G. Schrader, "A model for exponentially decaying inventory," Journal of Industrial Engineering, vol. 14, pp. 238-243, 1963.

[11] F. Raafat, "Inventory model for a system with monotonically increasing decay of raw materials and a decaying single finished product," International Journal of Systems Science, vol. 19, pp. 2625-2629, 1988.

[12] J. F. Jong and H. M. Wee, "A near optimal solution for integrated production inventory supplier-buyer deteriorating model considering JIT delivery batch," International Journal of Computer Integrated Manufacturing, vol. 21, pp. 289-300, 2008.

[13] P. C. Yang and H. M. Wee, "An integrated multi-lot-size production inventory model for deteriorating item," Computers and amp; Operations Research, vol. 30, pp. 671-682, 2003.

[14] H. J. Weiss, "Economic order quantity models with nonlinear holding costs," European Journal of Operational Research, vol. 9, pp. 56-60, 1982.

[15] M. Ferguson, V. Jayaraman, and G. C. Souza, "Note: An application of the EOQ model with nonlinear holding cost to inventory management of perishables," European Journal of Operational Research, vol. 180, pp. 485-490, 2007.

[16] O. Fujiwara and U. L. J. S. R. Perera, "EOQ models for continuously deteriorating products using linear and exponential penalty costs," European Journal of Operational Research, vol. 70, pp. 104-114, 1993.
[17] J. Blackburn and G. Scudder, "Supply chain strategies for perishable products: The case of fresh produce," Production and Operations Management, vol. 18, pp. 129-137, 2009

[18] A. Rong, R. Akkerman, and M. Grunow, "An optimization approach for managing fresh food quality throughout the supply chain," International Journal of Production Economics, vol. 131, pp. 421-429, 2011.

[19] A. Kramer, F. E. Bender, and S. Sirivichaya, "A generalized theory on rate of quality loss in foods," International Journal of Refrigeration, vol. 3, pp. 353-359, 1980.

[20] M. L. Entrup, H. O. Günther, P. Van Beek, M. Grunow, and T. Seiler, "Mixed-Integer Linear Programming approaches to shelf-life-integrated planning and scheduling in yoghurt production," International Journal of Production Research, vol. 43, pp. 5071-5100, 2005.

[21] M. Tsiros and C. M. Heilman, "The effect of expiration dates and perceived risk on purchasing behavior in grocery store perishable categories," Journal of Marketing, pp. 114-129, 2005.

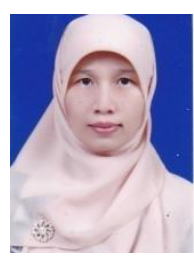

Gusti Fauza received the bachelor and master degree in industrial engineering from Andalas University and Institute Technology of Bandung Indonesia. Currently, she is a Ph.D. student of the School of Engineering in University of South Australia. Research in supply chain management, specifically inventory models, is her main interest. Now, she is working in inventory models for perishable items, especially food, from supply chain management perspective.

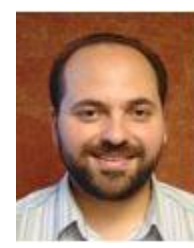

Yousef Amer holds a Ph.D. in mechanical and manufacturing engineering from the School of Engineering, University of South Australia. Currently he is a Program Director in the School of Engineering University of South Australia. $\mathrm{He}$ has 18 years' experience in automation, manufacturing, operations, logistics and supply chain management in various firms in Adelaide, both global and local. His research interests include simulation-based Lean Six-Sigma and Design for Six-Sigma, Artificial Intelligence, Manufacturing Strategy and Technology, Sustainability in Product and Service development, Lean and Green Supply Chain Modelling, Optimisation and Simulation and Sustainable Nano-manufacturing. He aims to develop links and collaboration with industry to foster relevant and innovate research. He has published books and many papers in academic journals, including International Journal of Production Economic and International Journal of Production Research, Journal Tribology International, and International Journal of Robotics and Computer Integrated Manufacturing.

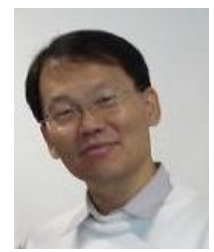

Sang Heon Lee received the Ph.D. degree in System Engineering from Australian National University. He is a senior lecturer in the School of Engineering, University of South Australia. His main research interests are in the area of Close-loop supply chain, discrete-event system and fuzzy logic control and neural networks. He has published many papers in academic journals, including International Journal of Production Economic, International Journal of Production Research, Journal Tribology International and International Journal of Robotics and Computer Integrated Manufacturing. 